\title{
AVALIAÇÃO DE INDICADORES ZOOTÉCNICOS E ECONÔMICOS EM SISTEMAS LEITEIROS COM DIFERENTES ESTRATOS DE TAMANHO
}

\author{
Elton Silva Resende* \\ Severino Delmar Junqueira Villela** \\ Fernando de Paula Leonel*** \\ Henrique Valentin Nunes Machado***** \\ Paulo Gustavo Macedo de Almeida Martins ${ }^{* * * * *}$ \\ Suely Jesus Oliveira******
}

RESUMO: Foram avaliados os principais indicadores zootécnicos, os componentes do custo de produção e os principais indicadores econômicos em fazendas produtoras de leite da região Norte de Minas Gerais, com diferentes estratos de tamanho. A discretização dos dados foi realizada pelo método não supervisionado de acordo com o número total de vacas no rebanho. Foram determinados os coeficientes de correlação linear entre os indicadores zootécnicos, os indicadores econômicos e os custos de produção, assim como parâmetros de regressão das variáveis com correlação significativa com a rentabilidade. Quanto à correlação os indicadores zootécnicos com maior influência nos custos unitários de produção foram a porcentagem de vacas em lactação, o número médio de dias em lactação, a produtividade média do rebanho, a eficiência de utilização da mão de obra e a produtividade por área. Somente o intervalo de partos apresentou correlação significativa com as margens bruta e líquida por litro de leite virtual. A porcentagem de vacas em lactação, a produtividade de animais em lactação e a produtividade por área apresentaram maior coeficiente de correlação com a rentabilidade. $\mathrm{Na}$ regressão, os indicadores zootécnicos porcentagem de vacas em lactação e a produtividade de vacas em lactação apresentaram valores negativos para o ponto de

* Mestre em Zootecnia pelo Programa de Pós-graduação em Zootecnia, Universidade Federal dos Vales do Jequitinhonha e Mucuri (UFVJM), Brasil. E-mail: eltonufsj@hotmail.com

** Doutor em Zootecnia, docente permanente do Programa de Pós-graduação em Zootecnia, Universidade Federal dos Vales do Jequitinhonha e Mucuri (UFVJM), Brasil.

*** Doutor em Zootecnia, docente permanente do Departamento de Zootecnia, Universidade Federal de São João del Rei (UFSJ), Brasil.

${ }^{* * * *}$ Doutor em Zootecnia, docente permanente do Departamento de Zootecnia, Universidade Federal de São João del Rei (UFSJ), Brasil.

Doutor em Zootecnia, docente do Instituto Federal do Norte de Minas Gerais, campus Almenara (IFNMG), Brasil .

${ }^{* * * * * *}$ Graduada em Agronomia pela Universidade Federal de Viçosa (UFV), Brasil. 
intercepto da variável dependente rentabilidade. Conclui-se que estratos com maior produtividade apresentaram menor custo operacional e menor margem líquida, o que não influenciou a obtenção de valores consideráveis de rentabilidade.

PALAVRAS-CHAVE: Análise econômica; Custos de produção; Rentabilidade.

\section{EVALUATION OF ANIMAL SCIENCE AND ECONOMIC INDEXES IN DAIRY SYSTEMS WITH DIFFERENT SIZE LAYERS}

ABSTRACT: The main animal science indexes, components of production costs and main economic indicators were assessed in dairy plantation in the north of the state of Minas Gerais, with different size layers. Data division was undertaken by nonsupervised method following the total number of cows in the herd. Coefficients of linear co-relationship, economic indexes, production costs, regression parameters of variables with significant co-relationship with profit were determined. Zootechnical indexes with the greatest influence in unit costs of production comprised percentage of milking cows, mean number of milking days, mean productivity of the herd, efficiency of labor and productivity per area. Birth intervals had a significant corelationship with gross and net margins per liter of virtual milk. Percentage of milking cows, productivity of milking animals and productivity per area had the greatest coefficient of co-relationship with profit. In the case of regression, zootechnical indexes milking cow percentage and productivity of milking cows provided negative rates for the interception point of the dependent variable profit. Results show that layers with greater productivity had lower operational costs and less net margin. The above did not affect significant rates in profit.

KEY WORDS: Economic analysis; Production costs; Profits.

\section{INTRODUÇÃO}

A análise econômica em propriedades leiteiras com diferentes estratos de tamanho gera importantes informações de desempenho, que podem ser utilizadas como referencial na tomada de decisão do fator gerencial. A definição de pontos de referência, denominados Benchmark, exibe elevada importância gerencial, visto que os valores são obtidos de sistemas de produção inseridos em um mesmo mercado (GOMES, 1999). Desta forma, os resultados podem ser utilizados na elaboração de 
novos projetos na atividade, demonstrando qual a melhor forma de investimento de capital no sistema de produção de leite.

De acordo com Ferraza et al. (2015), o acompanhamento de indicadores zootécnicos e econômicos pode ser empregado como ferramenta para o gerenciamento do desempenho técnico-econômico da atividade. Além disso, o conhecimento de indicadores em sistemas de produção com elevada eficiência econômica pode ser extremamente valioso, tornando-se referência para os demais sistemas (TUPY, 2011). Assim sendo, a análise dos indicadores zootécnicos e econômicos deve ser periodicamente, permitindo maior precisão de informações, minimizando o efeito de situações esporádicas e externas ao sistema de produção.

Tem sido estudado o efeito de diferentes características dos sistemas de produção de leite na rentabilidade da atividade leiteira, tais como a qualidade dos componentes do leite (TEIXEIRA JÚNIOR et al., 2015); emprego de diferentes níveis tecnológicos (FERRAZA et al., 2015). De maneira análoga, a avaliação do efeito de indicadores de tamanho de propriedades, no capital investido, nos custos de produção e nos indicadores econômicos entre estratos de tamanho, proporcionará embasamento técnico em auxilio à tomada de decisão na atividade leiteira.

Deste modo, os objetivos foram avaliar os principais índices zootécnicos, os componentes do custo de produção e os principais indicadores econômicos de fazendas produtoras de leite localizadas na região Norte de Minas Gerais, em diferentes estratos de tamanho, bem como realizar a correlação dos indicadores zootécnicos com os indicadores econômicos e os custos de produção fornecendo parâmetros de regressão.

\section{MATERIAL E MÉTODOS}

Foram coletados dados referentes às despesas, receitas e índices zootécnicos, durante o período compreendido entre os anos de 2007 e 2012 provindos de seis propriedades leiteiras situadas na região Norte do Estado de Minas Gerais e inseridos em planilhas do Microsoft Excel $^{\circledR}$ (Microsoft Corp., Redmond, WA, EUA) desenvolvidas especificamente para análises numéricas. 
A região está localizada a 465 metros de altitude, com latitude $16^{\circ} 44^{\prime}$ Sul e longitude $43^{\circ}$ 51' Leste de Greenwich. O clima é caracterizado como Aw, segundo a classificação de Köppen (1948), ou seja, tropical, quente com chuvas de verão e temperaturas médias anuais entre 22 e $24{ }^{\circ} \mathrm{C}$ e pluviosidade média anual entre 1000 e $1200 \mathrm{~mm}$.

A discretização dos dados, para redução do número de valores dos atributos contínuos para amplitude em intervalos, foi realizada pelo método não supervisionado. Desta forma, os sistemas de produção foram estratificados de acordo com o número total de vacas no rebanho, independentemente de estarem ou não em lactação. Assim, foram formados três intervalos de propriedades, sendo o menor com até 80 vacas no rebanho, o mediano entre 81 e 100 vacas no rebanho e o maior pertencente a propriedades com número de vacas acima de 100 .

A partir da discretização dos dados foram estipulados a área destinada à produção (pastagens, instalações e benfeitorias); o capital total investido e sua dispersão nos setores de produção, assim como a participação percentual de cada setor no total investido; e os tipos de mão de obra presentes nos diferentes estratos de tamanho das propriedades.

Os indicadores zootécnicos avaliados foram a porcentagem de vacas em lactação (vacas em lactação/total de vacas (\%)); a porcentagem de vacas em lactação em relação ao número total de animais do rebanho (vacas em lactação/total do rebanho (\%)); os dias em lactação (média de dias em lactação/total de vacas); produção total diária; produção média de vacas em lactação (produção total diária/ vacas em lactação); produção média do total de vacas (produção total diária/total de vacas); produção média total do rebanho (produção total diária/total do rebanho); intervalo de partos (intervalo de um parto e o parto seguinte em dias e meses).

$\mathrm{Na}$ definição do inventário completo dos bens de produção foram formadas as categorias pré-estabelecidas: benfeitorias, máquinas e equipamentos e animais de produção. O valor investido em cada categoria foi calculado segundo metodologia proposta por Lopes et al. (2004), por considerar o valor e a vida útil em relação ao tempo de aquisição.

Os custos de produção foram determinados segundo a metodologia do custo operacional proposta por Matsunaga et al. (1976). Para formação do Custo 
Operacional Efetivo (COE), foram consideradas as despesas com a mão de obra contratada (permanente e temporária), alimentação do rebanho (concentrados, volumosos e minerais), serviços profissionais (assistência técnica, serviços veterinários e de contabilidade), medicamentos e produtos veterinários e de higiene, manutenção de benfeitorias, inseminação artificial, manutenção de máquinas e equipamentos, manutenção de pastagens, adubos e defensivos agrícolas, energia elétrica, fretes, impostos e diversos custeios eventuais inerentes à atividade.

Para determinação do Custo Operacional Total (COT) foi somado ao montante do COE a depreciação e a remuneração da mão de obra familiar. Para o cálculo da depreciação foi utilizada a metodologia linear da depreciação proposta por Nogueira (2004).

A determinação da receita total da atividade foi dada pelo somatório das rendas obtidas pela venda do leite, dos animais e subprodutos, somados ao valor condizente da variação do inventário animal. A partir da determinação da receita, foi calculado o "equivalente em leite virtual (LV kg/ano)" obtido convertendo-se todas as receitas em equivalente leite, por meio da sua divisão pelo preço médio anual do leite pago ao produtor.

Na distinção dos estratos de tamanho, procedeu-se análise de variância dos indicadores considerados e testou-se a hipótese de igualdade das médias, quando necessário, por meio do teste de Tukey a um nível de significância de 5\%.

Para a determinação do impacto dos indicadores zootécnicos nos indicadores econômicos foram utilizados os procedimentos estatísticos de correlação linear de Pearson. Foram estimadas regressões para os indicadores zootécnicos que apresentaram correlação significativa com o indicador econômico rentabilidade. A significância estatística dos modelos gerados foi avaliada pelo teste estatístico $\mathrm{F}$. Todos os procedimentos estatísticos foram realizados mediante o uso do software estatístico SAS (SAS Institute Inc., Cary, NC, USA). 


\section{RESULTADOS}

No que se refere à análise dos indicadores zootécnicos entre as classes de tamanho avaliadas, propriedades com até 80 vacas no rebanho e propriedades com total de vacas acima de 100 obtiveram médias similares de porcentagem de vacas em lactação, sendo estes valores percentuais acima de $80 \%$ do total de vacas no rebanho (Tabela 1).

Para o indicador zootécnico produção total diária, não houve diferença para propriedades com até 100 vacas no rebanho $(\mathrm{P}<0,001)$. Entretanto, a produção obtida foi inferior ao estrato de propriedades com número superior a 100 vacas, que apresentou média de $1.360 \mathrm{~L} /$ dia. Propriedades com mais de 100 vacas no rebanho apresentaram menor coeficiente de variação, indicando menor discrepância de produção. $\mathrm{O}$ estrato com propriedades de menor tamanho apresentou maior produtividade por vaca em lactação e maior produtividade total do rebanho, quando comparado aos demais estratos de tamanho de propriedades.

Os indicadores de eficiência zootécnica relação matriz funcionários e relação litros de leite produzidos por funcionários apresentaram diferença $(P$ $<0,001)$ entre os estratos de tamanho. O indicador relação número de matriz/ funcionário apresentou diferentes níveis de eficiência em função do número de animais no rebanho, em que propriedades com maior número de matrizes apresentaram maiores médias. Quanto à relação litros de leite produzidos/ funcionário, a melhor relação foi exibida no estrato de propriedades acima de 100 vacas, com média de 339, 946 1/funcionário. Não houve diferença $(\mathrm{P}<0,001)$ entre os estratos com propriedades até 80 vacas no rebanho e de 81 a 100 vacas.

Tabela 1. Valores médios dos índices zootécnicos entre estratos de tamanho em seis propriedades leiteiras na região Norte do Estado de Minas Gerais

(Continua)

\begin{tabular}{|c|c|c|c|c|c|c|c|c|c|c|}
\hline \multirow{2}{*}{ Especificações } & \multicolumn{3}{|c|}{$<80$ vacas } & \multicolumn{3}{|c|}{ De 81 a 100 vacas } & \multicolumn{3}{|c|}{$>100$ vacas } & \multirow[b]{2}{*}{ P valor } \\
\hline & Média & & $\mathrm{CV}^{1}(\%)$ & Médias & & $\mathrm{CV}^{1}(\%)$ & Médias & & $\mathrm{CV}(\%)^{*}$ & \\
\hline VL, (\%) & 85,38 & $a$ & 2,55 & 70,51 & b & 8,52 & 80,05 & $\mathrm{a}$ & 3,73 & $<0,001$ \\
\hline DEL, (dias) & 174 & & 12,62 & 189 & & 17,6 & 205 & & 17,12 & 0,153 \\
\hline PTD, (kg) & 882 & b & 12,89 & 871 & b & 20,59 & 1360 & $\mathrm{a}$ & 7,88 & $<0,001$ \\
\hline PTA, (kg) & $322.034,82$ & $\mathrm{~b}$ & 12,89 & $317.825,05$ & $\mathrm{~b}$ & 20,59 & $496.320,66$ & $\mathrm{a}$ & 7,88 & $<0,001$ \\
\hline
\end{tabular}


(Conclusão)

\begin{tabular}{|c|c|c|c|c|c|c|c|c|c|c|}
\hline \multirow{2}{*}{ Especificações } & \multicolumn{3}{|c|}{$<80$ vacas } & \multicolumn{3}{|c|}{ De 81 a 100 vacas } & \multicolumn{3}{|c|}{$>100$ vacas } & \multirow[b]{2}{*}{ P valor ${ }^{* *}$} \\
\hline & Média & & $\mathrm{CV}^{1}(\%)$ & Médias & & $\mathrm{CV}^{1}(\%)$ & Médias & & $\mathrm{CV}(\%)^{*}$ & \\
\hline MVL, (kg) & 17,922 & $\mathrm{a}$ & 3,08 & 14,091 & b & 11,76 & 14,616 & $\mathrm{~b}$ & 8,04 & $<0,001$ \\
\hline MTR, (kg) & 16,3 & $\mathrm{a}$ & 16,26 & 9,985 & c & 18,2 & 11,689 & $\mathrm{~b}$ & 7,46 & $<0,001$ \\
\hline UNID. & 4 & b & 0 & 5 & $\mathrm{a}$ & 10,6 & 4 & $\mathrm{~b}$ & 0 & $<0,001$ \\
\hline RMF, (cabeças) & 14 & c & 8,85 & 19 & $\mathrm{~b}$ & 13,1 & 29 & $\mathrm{a}$ & 3,99 & $<0,001$ \\
\hline RLF, (kg/dia) & 220,572 & b & 12,89 & 194,24 & $\mathrm{~b}$ & 20,61 & 339,946 & a & 7,88 & $<0,001$ \\
\hline $\mathrm{Ha}$ & 69 & b & 0 & 203 & a & 5,59 & 209 & a & 1,25 & $<0,001$ \\
\hline PHA, (kg/ano) & $4.667,17$ & $\mathrm{a}$ & 12,89 & $1.573,40$ & c & 22,22 & $2.379,97$ & $\mathrm{~b}$ & 7,49 & $<0,001$ \\
\hline IP, (dias) & 407 & & 3,96 & 414 & & 7,48 & 416 & & 7,39 & 0,848 \\
\hline IP, (meses) & 13 & & 3,96 & 14 & & 7,48 & 14 & & 7,39 & 0,848 \\
\hline
\end{tabular}

${ }^{1}$ Coeficiente de variação. $\mathrm{VL}=$ Vacas em lactação; $\mathrm{DEL}=$ Dias em lactação; PTD $=$ Produção total diária; PTA = Produção total anual; MVL = Produtividade por vaca em lactação; MTR = Produtividade total do rebanho; UNID. = Número de funcionários; RMF = Relação matriz funcionário; RLF = Relação leite funcionário; Ha = Área de produção; PHA = Produção por hectare; IP = Intervalo de partos. "Coeficiente de variação. "Valor de probabilidade. Médias seguidas por letras idênticas na linha não diferem pelo teste Tukey. Fonte: Dados da pesquisa.

Quanto ao montante do COE, observou-se que o estrato de propriedades com mais de 100 vacas no rebanho apresentou maior valor monetário despendido, com média de $\mathrm{R} \$ 276.690,24$ (Tabela 2). Por outro lado, os estratos com propriedades com até 80 vacas e estratos de 81 a 100 vacas apresentaram média similares.

Dentre os itens que mais oneraram o COE, na avaliação entre estratos de tamanho de propriedades, destacou-se o gasto com alimentos concentrados. $\mathrm{O}$ estrato de tamanho de propriedades acima de 100 vacas obteve maior custo com este componente. A menor média obtida com gasto com concentrado foi de $\mathrm{R} \$$ $80.520,54$, exibida pelo estrato de propriedades com até 80 vacas no rebanho, porém este valor não diferiu $(\mathrm{P}=0,001)$ do valor médio obtido no estrato de propriedades com número total de vacas entre 81 e 100 animais no plantel.

O segundo item com maior participação no COE foi o gasto com a mão de obra permanente, apresentando similaridade das médias entre os estratos com propriedades com menos de 80 vacas e o estrato com propriedades com mais de 100 vacas no rebanho. 
Os estratos de tamanho de propriedades exibiram diferença $(\mathrm{P}<0,001)$ no desembolso com medicamentos e materiais de higiene de ordenha. O estrato de tamanho médio e o estrato de maior tamanho apresentaram maiores valores de desembolso com este componente do COE. Os altos coeficientes de variação observados em todos os estratos de tamanho indicam alta variabilidade quanto à utilização deste item nas propriedades avaliadas.

Tabela 2. Valores médios dos componentes do COE entre estratos de tamanho em seis propriedades leiteiras do Norte de Minas Gerais

\begin{tabular}{|c|c|c|c|c|c|c|c|c|c|c|}
\hline \multirow{2}{*}{$\begin{array}{l}\text { Especifica- } \\
\text { ções }\end{array}$} & \multicolumn{3}{|c|}{ Até 80 vacas } & \multirow{2}{*}{$\begin{array}{c}\text { De } 81 \text { a } 100 \\
\text { vacas }\end{array}$} & \multicolumn{6}{|c|}{ Acima de 100 vacas } \\
\hline & Médias & & $\begin{array}{l}\mathrm{CV}^{1} \\
(\%)\end{array}$ & & & $\begin{array}{l}\mathrm{CV}^{1} \\
(\%)\end{array}$ & Médias & & $\begin{array}{l}\mathrm{CV}^{1} \\
(\%)\end{array}$ & P valor \\
\hline $\begin{array}{l}\text { Mão de obra } \\
\text { permanente }\end{array}$ & $37.332,37$ & a & 8,00 & $26.613,14$ & $\mathrm{~b}$ & 28,31 & $40.265,08$ & a & 14,66 & $\begin{array}{c}< \\
0,001\end{array}$ \\
\hline (\%) & 22,03 & & & 14,63 & & & 14,55 & & & \\
\hline $\begin{array}{l}\text { Serviços pro- } \\
\text { fissionais }\end{array}$ & $7.251,60$ & $\mathrm{a}$ & 14,09 & $6.100,34$ & $\mathrm{a}$ & 24,08 & $5.620,28$ & $\mathrm{a}$ & 22,51 & 0,065 \\
\hline (\%) & 4,28 & & & 3,35 & & & 2,03 & & & \\
\hline $\begin{array}{l}\text { Concentra- } \\
\text { dos }\end{array}$ & $80.520,54$ & $\mathrm{~b}$ & 39,3 & $91.633,66$ & $\mathrm{~b}$ & 34,23 & $128.125,25$ & $\mathrm{a}$ & 12,96 & 0,001 \\
\hline (\%) & 47,51 & & & 50,37 & & & 46,31 & & & \\
\hline Volumosos & $8.298,33$ & $\mathrm{~b}$ & 21,24 & $10.674,37$ & $a b$ & 39,28 & $14.708,92$ & $\mathrm{a}$ & 43,06 & 0,023 \\
\hline (\%) & 4,90 & & & 5,87 & & & 5,32 & & & \\
\hline $\begin{array}{l}\text { Mistura } \\
\text { mineral }\end{array}$ & $4.832,21$ & $\mathrm{~b}$ & 21,42 & $3.716,27$ & $\mathrm{~b}$ & 76,88 & $12.216,92$ & a & 16,6 & $\begin{array}{c}< \\
0,001\end{array}$ \\
\hline (\%) & 2,85 & & & 2,04 & & & 4,42 & & & \\
\hline $\begin{array}{l}\text { Medicamen- } \\
\text { tos e higiene }\end{array}$ & $5.429,23$ & $\mathrm{~b}$ & 48,59 & $10.030,47$ & $\mathrm{a}$ & 37,34 & $12.875,33$ & a & 17,59 & $\begin{array}{c}< \\
0,001\end{array}$ \\
\hline$(\%)$ & 3,20 & & & 5,51 & & & 4,65 & & & \\
\hline $\begin{array}{l}\text { Material de } \\
\text { construção }\end{array}$ & $4.915,03$ & & 65,75 & $3.150,33$ & & 89,97 & $5.710,58$ & & 155,64 & 0,485 \\
\hline (\%) & 2,90 & & & 1,73 & & & 2,06 & & & \\
\hline $\begin{array}{l}\text { Energia/ } \\
\text { Combustível }\end{array}$ & $8.039,50$ & $\mathrm{~b}$ & 16,57 & $14.823,70$ & b & 39,38 & $35.673,16$ & $\mathrm{a}$ & 24,85 & $\begin{array}{c}< \\
0,001\end{array}$ \\
\hline (\%) & 4,74 & & & 8,15 & & & 12,89 & & & \\
\hline
\end{tabular}




\begin{tabular}{|c|c|c|c|c|c|c|c|c|c|c|}
\hline \multirow{2}{*}{$\begin{array}{l}\text { Especifica- } \\
\text { ções }\end{array}$} & \multicolumn{3}{|c|}{ Até 80 vacas } & \multicolumn{2}{|l|}{$\begin{array}{c}\text { De } 81 \text { a } 100 \\
\text { vacas }\end{array}$} & \multicolumn{5}{|c|}{ Acima de 100 vacas } \\
\hline & Médias & & $\begin{array}{l}\mathrm{CV}^{1} \\
(\%)\end{array}$ & Médias & & $\begin{array}{l}\mathrm{CV}^{1} \\
(\%)\end{array}$ & Médias & & $\begin{array}{l}\mathrm{CV}^{1} \\
(\%)\end{array}$ & P valor \\
\hline $\begin{array}{l}\text { Máquinas e } \\
\text { equipamen- } \\
\text { tos }\end{array}$ & $7.414,80$ & $\mathrm{~b}$ & 15,16 & $8.122,28$ & $\mathrm{~b}$ & 73,58 & $15.314,92$ & a & 48,67 & 0,007 \\
\hline (\%) & 4,38 & & & 4,46 & & & 5,54 & & & \\
\hline Inseminação & $2.201,37$ & & 70,06 & $3.642,36$ & & 74,16 & $2.579,23$ & & 31,8 & 0,234 \\
\hline (\%) & 1,30 & & & 2,00 & & & 0,93 & & & \\
\hline Diversos & $2.693,53$ & & 61,62 & $1.940,07$ & & 60,77 & $2.443,17$ & & 65,46 & 0,453 \\
\hline (\%) & 1,59 & & & 1,07 & & & 0,88 & & & \\
\hline$(\%)$ & 0,32 & & & 0,82 & & & 0,42 & & & \\
\hline TOTAL & $169.463,51$ & $\mathrm{~b}$ & 22,16 & $181.937,61$ & $\mathrm{~b}$ & 30,04 & $276.690,24$ & $\mathrm{a}$ & 10,42 & $<0,001$ \\
\hline
\end{tabular}

"Coeficiente de variação. "Valor de probabilidade. Médias seguidas por letras idênticas na mesma linha não diferem estatisticamente pelo teste Tukey a 5\%.

Fonte: Dados da pesquisa.

Avaliando a receita total, verificou-se que o estrato de propriedades com mais de 100 vacas no rebanho apresentou maior média de receita total (Tabela 3). Os valores médios de receita total obtidos nos estratos de tamanho com número de vacas entre 81 e 100 vacas, e de até 80 vacas, no rebanho foram similares. Todos os estratos de tamanho apresentaram margens bruta e líquida positivas, com o estrato de propriedades de maior tamanho com médias superiores para estes indicadores.

No diagnóstico econômico, os estratos com até 80 vacas e o com mais de 100 vacas no rebanho apresentaram média superior de rentabilidade sobre o capital imobilizado (Rentabilidade > 9,50\%).

A análise estatística dos indicadores de referência unitários não apresentou variações significativas $(\mathrm{P}>0,082)$ dentre os estratos de tamanho analisados. 
Tabela 3. Valores médios dos indicadores econômicos da atividade leiteira, em Reais, entre estratos de tamanho em seis propriedades leiteiras na região Norte do Estado de Minas Gerais

\begin{tabular}{|c|c|c|c|c|c|c|c|c|c|}
\hline \multirow[b]{2}{*}{ Especificações } & \multicolumn{3}{|c|}{ Até 80 vacas } & \multicolumn{3}{|c|}{ De 81 a 100 vacas } & \multicolumn{2}{|c|}{ Acima de 100 vacas } & \multirow[b]{2}{*}{ P valor } \\
\hline & Médias & & $\begin{array}{l}\mathrm{CV}^{1} \\
(\%)\end{array}$ & Médias & & $\begin{array}{l}\mathrm{CV}^{1} \\
(\%)\end{array}$ & Médias & $\begin{array}{l}\mathrm{CV} \\
(\%)^{*}\end{array}$ & \\
\hline Receitas, (R\$) & 294.426 & B & 17,53 & 298.155 & b & 23,11 & 467.818 & a $\quad 15,78$ & $\begin{array}{c}< \\
0,001\end{array}$ \\
\hline Leite virtual, (L) & 399.099 & B & 11,8 & 413.268 & b & 16,96 & 631.148 & 7,29 & $\begin{array}{c}< \\
0,001\end{array}$ \\
\hline COT, $(\mathrm{R} \$)$ & 190.924 & B & 20,6 & 207.639 & b & 27,72 & 302.335 & 9,42 & $\begin{array}{c}< \\
0,001\end{array}$ \\
\hline $\mathrm{COE},(\mathrm{R} \$)$ & 172.780 & B & 22,16 & 183.955 & b & 29,39 & 282.102 & a 10,42 & $\begin{array}{c}< \\
0,001\end{array}$ \\
\hline $\begin{array}{l}\text { Margem bruta, } \\
(\mathrm{R} \$)\end{array}$ & 121.646 & B & 27,14 & 114.199 & $\mathrm{~b}$ & 39,09 & 185.715 & 33,9 & 0,002 \\
\hline $\begin{array}{l}\text { Margem líquida, } \\
(\mathrm{R} \$)\end{array}$ & 103.502 & B & 31,49 & 90.515 & $\mathrm{~b}$ & 47,62 & 165.483 & a 37,52 & 0,001 \\
\hline $\begin{array}{l}\text { Rentabilidade, } \\
(\%)\end{array}$ & 12,26 & A & 32,72 & 6,37 & $\mathrm{~b}$ & 40,32 & 9,5 & a 27,76 & $\begin{array}{c}< \\
0,001 \\
\end{array}$ \\
\hline $\begin{array}{l}\mathrm{COE} / \mathrm{Litro} \text { de } \\
\text { leite, }(\mathrm{R} \$ \mathrm{~L})\end{array}$ & 0,44 & & 23,29 & 0,45 & & 8,98 & 0,44 & 17,41 & 0,614 \\
\hline $\begin{array}{l}\text { COE leite/preço } \\
\text { leite, }(\%)\end{array}$ & 58,92 & & 14,56 & 61,22 & & 13,38 & 61,35 & 17,74 & 0,242 \\
\hline $\begin{array}{l}\text { COT/Litro de } \\
\text { leite }(\mathrm{R} \$ \mathrm{~L})\end{array}$ & 0,48 & & 21,86 & 0,48 & & 8,03 & 0,50 & 16,17 & 0,274 \\
\hline $\begin{array}{l}\text { COT leite/preço } \\
\text { leite, }(\%)\end{array}$ & 65,23 & & 13,90 & 65,64 & & 12,87 & 69,22 & 16,96 & 0,093 \\
\hline $\begin{array}{l}\text { MB/Litro de leite, } \\
(\mathrm{R} \$)\end{array}$ & 0,30 & & 18,83 & 0,29 & & 30,21 & 0,28 & 33,45 & 0,951 \\
\hline $\begin{array}{l}\text { ML/Litro de leite, } \\
(\mathrm{R} \$)\end{array}$ & 0,25 & & 23,87 & 0,26 & & 33,79 & 0,23 & 43,00 & 0,821 \\
\hline
\end{tabular}

$\overline{\mathrm{COE}}=$ Custo operacional efetivo; $\mathrm{COT}=$ Custo operacional total.

Coeficiente de variação. "Valor de probabilidade. Médias seguidas por letras idênticas na mesma linha não diferem estatisticamente pelo teste Tukey.

Fonte: Dados da pesquisa.

O intervalo de partos apresentou correlação significativa com as margens bruta e líquida por litro de leite virtual $(\mathrm{P}=0,007)$. Entretanto, um maior o número 
de indicadores zootécnicos (Tabela 4) atuaram significantemente na determinação da rentabilidade dos sistemas de produção, destaque para a porcentagem de vacas em lactação, a produtividade de animais em lactação e a produtividade por área ( $\mathrm{P}$ $<0,007)$.

Tabela 4. Valores de correlação de Pearson e valores de significância estatística (P valor) entre indicadores zootécnicos e econômicos obtidos entre estratos de tamanho em seis propriedades leiteiras na região Norte do Estado de Minas Gerais

\begin{tabular}{|c|c|c|c|c|c|}
\hline Indicadores & $\mathrm{COE} / \mathrm{LV}$ & COT/LV & $\mathrm{MB} / \mathrm{LV}$ & $\mathrm{ML} / \mathrm{LV}$ & Rent. \\
\hline \multirow{2}{*}{ Vacas em lactação, (\%) } & $-0,921^{* *}$ & $-0,914^{* *}$ & $0,709^{\text {ns }}$ & $0,706^{\mathrm{ns}}$ & $0,524^{* * *}$ \\
\hline & 0,009 & 0,009 & 0,114 & 0,117 & 0,001 \\
\hline \multirow{2}{*}{ Dias em lactação, (Dias) } & $0,945^{* *}$ & $0,943^{* *}$ & $-0,789$ & $-0,782$ & $-0,168^{\mathrm{ns}}$ \\
\hline & 0,005 & 0,005 & 0,062 & 0,066 & 0,335 \\
\hline \multirow{2}{*}{ Produção total diária, (L) } & $-0,810^{*}$ & $-0,801$ & $0,651^{\mathrm{ns}}$ & $0,648^{\text {ns }}$ & $0,251^{\text {ns }}$ \\
\hline & 0,050 & 0,051 & 0,161 & 0,164 & 0,146 \\
\hline \multirow{2}{*}{ Produtividade de vacas em lactação, (L) } & $-0,464^{\mathrm{ns}}$ & $-0,480^{\mathrm{ns}}$ & $-0,465^{\mathrm{ns}}$ & $-0,463^{\mathrm{ns}}$ & $0,449^{* *}$ \\
\hline & 0,354 & 0,335 & 0,353 & 0,355 & 0,007 \\
\hline \multirow{2}{*}{ Produtividade total do rebanho, (L) } & $-0,841^{*}$ & $-0,837^{*}$ & $0,670^{\text {ns }}$ & $0,666^{\mathrm{ns}}$ & $0,472^{* *}$ \\
\hline & 0,036 & 0,037 & 0,145 & 0,149 & 0,004 \\
\hline \multirow{2}{*}{ Relação matriz funcionários, (Unid.) } & $-0,888^{*}$ & $-0,869^{*}$ & $0,664^{\mathrm{ns}}$ & $0,655^{\mathrm{ns}}$ & $0,101^{\mathrm{ns}}$ \\
\hline & 0,018 & 0,025 & 0,151 & 0,158 & 0,565 \\
\hline \multirow{2}{*}{ Relação leite funcionários, (L) } & $-0,819^{*}$ & $-0,821^{*}$ & $0,670^{\text {ns }}$ & $0,667^{\mathrm{ns}}$ & $0,343^{*}$ \\
\hline & 0,046 & 0,045 & 0,1455 & 0,148 & 0,044 \\
\hline \multirow{2}{*}{ Produtividade por área, (L) } & $-0,800$ & $-0,767$ & $0,522^{\mathrm{ns}}$ & $0,0513^{\mathrm{ns}}$ & $0,587^{* * *}$ \\
\hline & 0,056 & 0,075 & 0,288 & 0,299 & 0,0002 \\
\hline \multirow{2}{*}{ Intervalo de partos, (Dias) } & $0,695^{\mathrm{ns}}$ & 0,765 & $-0,932^{* *}$ & $-0,933^{* *}$ & $-0,416^{*}$ \\
\hline & 0,125 & 0,076 & 0,007 & 0,007 & 0,013 \\
\hline \multirow{2}{*}{ Preço médio do leite, $(\mathrm{R} \$)$} & $-0,377^{\text {ns }}$ & $0,492^{\mathrm{ns}}$ & $0,805^{*}$ & $0,819^{*}$ & 0,316 \\
\hline & 0,462 & 0,322 & 0,050 & 0,046 & 0,064 \\
\hline \multirow{2}{*}{ Porcentagem de receita do leite, (\%) } & $0,342^{\mathrm{ns}}$ & $0,457^{\mathrm{ns}}$ & $-0,765$ & $-0,700$ & $-0,112^{\mathrm{ns}}$ \\
\hline & 0,507 & 0,362 & 0,076 & 0,067 & 0,524 \\
\hline
\end{tabular}

Os valores subscritos correspondem ao nível descritivo de probabilidade para o erro tipo I associado a hipóteses de nulidade. ${ }^{*} \mathrm{P}<0,05 ;$;* $\mathrm{P}<0,01 ;$ *** $\mathrm{P}<0,001 ; \mathrm{e}^{\text {ns }}$ não significativo.

$\mathrm{COE} / \mathrm{LV}=$ Custo operacional efetivo unitário; COT/LV = Custo operacional total unitário; $\mathrm{MB} / \mathrm{LV}=$ Margem bruta unitária; $\mathrm{ML} / \mathrm{LV}=$ Margem líquida unitária; e Rent. = rentabilidade.

Fonte: Dados da pesquisa.

As equações geradas por parâmetros de regressão, a partir dos indicado- 
res zootécnicos que obtiveram correlação linear significativa com a rentabilidade, denotaram a influência matemática do indicador zootécnico no comportamento da rentabilidade do sistema (Tabela 5). Avaliando o coeficiente de determinação, que indica a quantidade de variabilidade nos dados explicada pelo modelo de regressão ajustado, observou-se que os indicadores zootécnicos com maior coeficiente de determinação foram a produtividade por área $\left(\mathrm{R}^{2}=0,34\right)$, seguido pela porcentagem de vacas em lactação $\left(R^{2}=0,27\right)$. Já os indicadores com menores coeficientes de determinação foram o preço médio do leite $\left(\mathrm{R}^{2}=0,10\right)$ e a relação leite funcioná$\operatorname{rios}\left(\mathrm{R}^{2}=0,12\right)$.

Os indicadores porcentagem de vacas em lactação e a produtividade de vacas em lactação apresentaram valores negativos para o parâmetro de regressão o, ponto referente ao intercepto da variável dependente, de -9,99135 e -3,50958, respectivamente. Por outro lado, o intervalo de partos apresentou valor positivo e elevado para o parâmetro de regressão $\beta_{0}(29,98476)$.

Tabela 5. Parâmetros de regressão, valores de significância estatística (P valor) e coeficiente de determinação $\left(\mathrm{R}^{2}\right)$ de rentabilidade em função de diferentes indicadores zootécnicos e de setores de investimento de capital em função do capital investido em animais, obtidos entre estratos de tamanho em seis propriedades leiteiras na região Norte do Estado de Minas Gerais

\begin{tabular}{|c|c|c|c|c|}
\hline Variável dependente & Siglas & $\begin{array}{l}\text { Parâmetros da equação de } \\
\text { regressão }\end{array}$ & P valor & $\mathrm{R}^{2}$ \\
\hline Vacas em lactação, (\%) & $\mathrm{VL}$ & $\begin{array}{c}\text { RENT }=-9,99135+0,24431 \\
\text { VL }\end{array}$ & 0,0012 & 0,27 \\
\hline $\begin{array}{l}\text { Média de vacas em lactação, } \\
\text { (L) }\end{array}$ & MVL & $\begin{array}{c}\text { RENT }=-3,50958+0,81502 \\
\text { MVL }\end{array}$ & 0,0068 & 0,20 \\
\hline Média total do rebanho, (L) & MTR & $\begin{array}{c}\text { RENT }=1,83493+0,58550 \\
\text { MTR }\end{array}$ & 0,0042 & 0,22 \\
\hline Relação leite funcionários, (L) & RLF & $\begin{array}{c}\text { RENT }=4,67647+0,01600 \\
\text { RLF }\end{array}$ & 0,0439 & 0,12 \\
\hline Produtividade por área, (L) & PHA & $\begin{array}{c}\text { RENT }=4,46142+0,00176 \\
\text { PHA }\end{array}$ & 0,0002 & 0,34 \\
\hline Intervalo de partos, (Dias) & IP & $\begin{array}{c}\text { RENT }=29,98476-0,05159 \\
\text { IP }\end{array}$ & 0,0130 & 0,17 \\
\hline Preço médio do leite, $(\mathrm{R} \$)$ & PRECO & $\begin{array}{c}\text { RENT }=0,28206+8,85884 \\
\text { PRECO }\end{array}$ & 0,0600 & 0,10 \\
\hline
\end{tabular}

"Coeficiente de significância do teste F.

Fonte: Dados da pesquisa. 


\section{DISCUSSÃO}

A porcentagem de vacas em lactação apresentou valores consideráveis em todos os estratos de tamanho, próximos aos $83,3 \%$ de vacas em lactação recomendados por Lins; Vilela (2006), obtidos através de uma situação ideal com 305 dias de lactação e intervalo de parto de 12 meses. Sousa et al. (2011) encontraram média de vacas em lactação de 50,0\%. Mesmo a menor média encontrada (70,5\%) no estrato de 81 a 100 é superior ao valor reportado por estes autores.

O maior valor médio de porcentagem de vacas em lactação, aliado à maior produtividade de vacas em lactação das propriedades com até 80 vacas no rebanho, permitiu a obtenção de valor médio similar de produção diária de leite ao estrato de 81 a 100 vacas, destacando a importância de rebanhos com bons índices produtivos e reprodutivos para obtenção de elevado nível de produção diária. Entretanto, a maior produtividade por vaca em lactação no estrato de propriedades com até 80 vacas foi insuficiente para alcançar a produção diária do estrato com propriedades com mais de 100 vacas no rebanho. No longo prazo, o aumento de dias em lactação do estrato de propriedades de menor tamanho determinaria aumento na produção diária, com valor superior possível ao estrato de propriedades de maior tamanho.

A relação matriz/funcionário do estrato com maior produtividade para este fator de produção foi superior a relação reportada por Lopes et al. (2004) e Lopes et al. (2006), com valores acima de 18 matrizes por funcionário. Moraes et al. (2016) encontraram valores médios superiores de 26,38 matrizes/funcionário em propriedades que utilizam somente a mão de obra contratada, demonstrando que a utilização deste tipo de mão de obra apresenta melhor relação matriz funcionário que propriedades que utilizam a mão de obra mista e ou apenas a mão de obra familiar.

As diferenças nas médias de produtividade por unidade de área nos estratos avaliados deveram-se a taxa de lotação animal e da produtividade animal. De fato, Ribeiro et al. (2008) condicionaram a produtividade por área em função do desempenho animal e pela taxa de lotação. A principal variável determinante da taxa de lotação animal é a condição da pastagem, tanto em quantidade como em qualidade. Desta forma, o alcance de um bom nível de produtividade das pastagens 
depende do desenvolvimento de novas técnicas de manejo, aspectos genéticos, e a otimização da utilização da forrageira que tratam ações e interações do genótipo com o ambiente no qual está inserida (MARTURSCELLO et al., 2007).

As variações existentes nas médias de receita bruta obtidas entre os três estratos de produção podem ser explicadas em função da quantidade de leite produzida e comercializada, em que o estrato de maior tamanho obteve média superior de receita total, oriunda da elevada comercialização de leite. De maneira análoga ao estudo de Lopes et al. (2006), os valores de participação da venda de subprodutos, tais como esterco, na formação da receita, não apresentaram participação considerável em nenhum dos estratos de tamanho avaliados. De acordo com Lopes et al. (2004), a utilização deste componente na adubação de culturas forrageiras promove uma redução significativa nas despesas com manutenção de capineiras e canaviais, explicando a baixa participação deste componente na formação da receita total.

$\mathrm{Na}$ avaliação da quantidade em equivalente de leite virtual obtida em cada um dos estratos notou-se que o estrato de maior tamanho apresentou média superior aos demais estratos, confirmando o esperado, pois exibiram maiores valores de venda de animais, variação de inventário animal e produção de leite, todos estes valores proporcionados pelo maior número de animais com bons níveis de produção. De maneira geral, quanto menor a participação da renda do leite na formação da receita total, maior tende a ser o valor de equivalente em leite virtual. Entretanto, a relação das rendas da atividade leiteira em propriedades com menos de 100 vacas no rebanho não foi suficiente para proporcionar similaridade nas médias obtidas.

O agrupamento do custo operacional efetivo em componentes permite a avaliação específica dos desembolsos realizados pelo sistema de produção de leite e, de maneira concisa, auxiliando técnicos e produtores na elaboração de uma análise detalhada (LOPES; LOPES, 1999).

$\mathrm{O}$ gasto com alimentos concentrados apresentou maior desembolso em todos os estratos de tamanho avaliados, corroborando o relato de Nascif (2014) ao relatar que o gasto com alimentos concentrados é o principal componente dos custos de produção. Os valores médios de desembolso com concentrado foram 
similares entre os estratos com propriedades de menor e médio tamanho e podem ser explicados pela maior produtividade por vaca no estrato de propriedades de menor tamanho, visto que em todas as propriedades recomendou-se a alimentação concentrada, na proporção de $1 \mathrm{~kg}$ de ração para cada $3 \mathrm{~kg}$ de leite produzidos.

Comparando a utilização da mão de obra permanente nos estratos de propriedades de maior e menor tamanho, ficou evidente a maior eficiência de utilização deste componente para o estrato de maior tamanho, pois apresentou desembolso similar ao estrato de menor tamanho, porém com maior relação litros por funcionário e maior relação matriz/funcionário, otimizando a utilização deste componente com grande participação na formação do COE. De maneira geral, o fator mão de obra familiar, inexistente nas propriedades deste estudo, é comumente citado como agente redutor dos desembolsos com mão de obra permanente (LOPES et al., 2006).

A produtividade por vaca, juntamente com a quantidade de vacas ordenhadas, afetou o comportamento dos desembolsos na maioria dos componentes do COE em todos os estratos de tamanho de propriedades. Estratos com maior produtividade apresentaram diluição nos custos de determinados componentes do COE. De fato, Lopes et al. (2004) e Moraes et al. (2016) mencionaram o aumento da eficiência produtiva como alternativa de otimização das despesas com mão de obra, inseminação artificial, energia, medicamentos, impostos fixos e despesas diversas.

O tamanho das propriedades influenciou o COT dos sistemas de produção do leite. O maior valor médio de COT apresentado pelo estrato de propriedades de maior tamanho esteve vinculado ao maior valor de COE, que por sua vez esteve ligado ao número de vacas em lactação, à produtividade animal e à produção diária total. De fato, notou-se similaridade de média entre os estratos de propriedades de médio e menor tamanho, tanto para a produção de leite e COE, quanto para COT. Lopes et al. (2006) encontraram valores de COT variando em função da escala de produção de leite, em propriedades com produções diárias de 151, 181 e $400 \mathrm{~kg}$ / dia, apresentando variações percentuais de COT de $247 \%$ superior na produção de $181 \mathrm{~kg} /$ dia em relação à produção de $151 \mathrm{~kg} /$ dia e mais de 500\% na relação entre as produções de 181 e $400 \mathrm{~kg} / \mathrm{dia}$.

Os valores de receita total em todos os estratos de tamanho foram 
suficientes para cobrir os custos operacionais efetivos gerados na atividade leiteira. Desta forma, os estratos apresentaram valores médios positivos de margem bruta, com todos os estratos exibindo condições de sobreviver no curto prazo. O valor similar margem bruta nos estratos de menor e médio tamanho ocorreu em razão do comportamento similar dos custos de produção para obtenção de mesma receita. Assim, a maior produtividade animal, maior produtividade da mão de obra e maior produtividade por unidade de área, fatores regidos pelo gerenciamento da propriedade, foram condicionantes para o elevado valor de margem bruta obtida no estrato de propriedades com menor tamanho.

$\mathrm{O}$ valor positivo de margem líquida nos estratos de tamanho avaliados possibilitou às propriedades elevado nível de estabilidade no longo prazo. Ainda, condicionou valores positivos de rentabilidade, possibilitando constante processo de expansão e a manutenção no mercado em longo prazo, com processo gradativo de capitalização dos produtores.

A rentabilidade mede a capacidade da atividade de gerar rendimentos em relação ao capital total disponível, demonstrando uma relação percentual entre a margem líquida obtida e esse capital. De maneira geral, todos os estratos de tamanho apresentaram valores consideráveis de rentabilidade, superiores a valores de atratividade fornecidos em setores de investimentos alternativos. Os estratos estudados apresentaram valor médio de rentabilidade acima dos 6,00\%, valor limiar comumente utilizado como de indicativo de eficiência econômica. $\mathrm{O}$ estrato de produção de menor tamanho apresentou melhor eficiência na utilização do capital, principalmente por apresentar maior taxa de lotação, maior produtividade por área e maior produtividade por animal, possibilitando aumento de rentabilidade.

A elevada correlação negativa entre produção total diária e o COT/LV indica que, possivelmente, o aumento de produção diária refletiu na diluição do custo com a depreciação, tratado em algumas metodologias como um custo fixo de produção, ou seja, custos que permanecem estáveis em função de variações nos níveis de produção (REIS, 2002). Marques et al. (2002), avaliando os custos de produção em função da escala de produção na pecuária leiteira, identificaram padrão similar, em que maiores produções diárias relacionaram-se diretamente com a diluição ou redução dos custos fixos. 
A correlação negativa existente entre a relação matriz por funcionários e os custos de produção ratifica a importância do aumento da produtividade da mão de obra visando à redução dos custos de produção. Nascif (2008) destacou que o aumento da produtividade da mão de obra apresenta impacto redutivo direto no custo operacional efetivo, e sua obtenção é mediada através de treinamento pessoal, capacitação, bonificação por resultados, estabelecimento de rotina de trabalho, estabelecimento de metas e a mecanização das atividades.

No caso do elevado coeficiente de correlação entre o intervalo de partos e as margens bruta e líquida, possibilitou identificá-lo como principal indicador zootécnico avaliado. De fato, inúmeros fatores de impacto econômico se relacionam com o intervalo de partos. Santos et al. (2001) relataram que a redução do intervalo de partos interfere no aumento do número de nascimento de bezerras. Isto impacta diretamente na formação do plantel animal, no contingente de animais para reposição (BERETTA; LOBATO; MIELITZ, 2001) e possíveis vendas de animais, fatores que impactam diretamente no aumento de produtividade e formação de renda que possui participação direta na constituição da receita total da atividade leiteira. Lopes et al. (2009), ao quantificarem o impacto econômico do intervalo de partos em rebanhos de gado de leite, mencionaram que animais em longos períodos de improdutividade são os grandes responsáveis pelo aumento de custos com alimentação, mão de obra e medicamentos.

Quanto à análise da correlação dos principais indicadores de produtividade com a rentabilidade do sistema de produção leiteira, para todos os setores, seja relacionado à produtividade animal, ou mesmo à produtividade da terra, os valores foram significativos e estiveram correlacionados positivamente. Desta forma, tanto técnicos quanto proprietários devem estar voltados à busca de melhorias nos indicadores de produtividade, objetivando melhorias na eficiência econômica de sistemas de produção de leite, ou seja, o aumento do desempenho desses indicadores tende a elevar a rentabilidade.

Neste estudo não foi obtida correlação significativa entre a produção total diária com a rentabilidade. De fato, Camilo Neto (2008) destacou que determinado sistema de produção de leite pode apresentar alta produção diária com baixos rendimentos, caso os gastos despendidos sejam incompatíveis com o nível de 
produção, havendo necessidade de compatibilidade com o aumento da produção com um controle rigoroso dos custos de produção.

A correlação entre a porcentagem de vacas em lactação e a rentabilidade apresentou maiores valores de coeficiente correlação e maior significância, quando comparados aos resultados encontrados por Nascif (2008), que analisou indicadores econômicos de referência em propriedades de Central Mineira, Sul/Sudoeste de Minas, Triângulo Mineiro/Alto Paranaíba e Vale do Mucuri. Os maiores valores desta correlação, encontrados nesta pesquisa, provavelmente se deram a maior porcentagem de participação da renda do leite na formação da receita total.

A elevada correlação entre a produtividade da terra e a rentabilidade foi devida à maneira de investimento do capital, que é determinante para obtenção do valor de rentabilidade, pois a produtividade da terra engloba os principais setores de investimento de capital, sendo o setor animais e o setor terras. Oliveira et al. (2007) também encontraram correlação positiva entre a produtividade da terra e a rentabilidade com valor de coeficiente de correlação, destacando a importância deste recurso no desempenho econômico da atividade leiteira.

A grande maioria dos produtores elenca o preço do leite como principal critério para a obtenção de valores significativos de rentabilidade, mas o presente estudo demonstrou apenas tendência de correlação entre o preço do leite e este indicador econômico. Assim, vale ressaltar que a variação no preço do leite atuou com discrição na formação do valor de rentabilidade. Para o aumento de rentabilidade, verificou-se maior importância de indicadores de produtividade, inerentes ao sistema de produção, quando comparados ao preço pago pelo leite, variável externa ao sistema de produção e com baixa atuação do fator gerencial.

As equações de regressão geradas permitiram a realização de simulações dos valores, contidos no intervalo de dados, dos diferentes indicadores zootécnicos para obtenção de valores independentes de rentabilidade. Desta forma, comportaram a realização de um comparativo entre valores já descritos na literatura. Lopes et al. (2015) avaliaram o efeito de alguns índices técnicos e gerenciais na rentabilidade de unidades demonstrativas de nível tecnológico mediano, encontraram valores de $72,93 \%$ para porcentagem de vacas em lactação, para produtividade de vacas em lactação de 14,343 L/dia e relação leite funcionários de 181,370 L/funcionário, 
considerando $6,09 \%$ de rentabilidade. Todos os valores foram superiores quando comparados aos mesmos indicadores zootécnicos obtidos por simulação no presente estudo, para obtenção de valor de rentabilidade similar.

Já Ferraza et al. (2015), analisando diferentes níveis tecnológicos sobre a rentabilidade da atividade leiteira, encontraram valor médio de rentabilidade de $11,4 \%$ em sistemas de produção de médio nível tecnológico. Para tal, foram necessários 12,043 L/animal/dia de produtividade de vacas em lactação e relação produção de leite/funcionários de 144,6 L/funcionário, valores inferiores aos simulados no presente estudo. Porém, o valor de produtividade por área foi muito superior (5.949,50 L/ha/ano) ao valor simulado no presente estudo, de 3.942,375 L/ ha/ano.

\section{CONSIDERAÇÕES FINAIS}

Estratos de tamanho com maior produtividade da terra apresentam melhor taxa de giro de capital alcançando maiores valores de rentabilidade. Além disso, considerando o caráter dinâmico do ambiente que envolve os sistemas de produção de leite, fica evidente a necessidade da identificação e quantificação periódica dos indicadores de produtividade.

A porcentagem de vacas em lactação, o número médio de dias em lactação, a produtividade média do rebanho, a eficiência de utilização da mão de obra influenciam diretamente os custos unitários de produção. $\mathrm{O}$ intervalo de partos apresenta-se como principal indicador zootécnico, por possuir elevada correlação com a margem bruta, margem líquida e também com a rentabilidade. As correlações e os parâmetros de regressão permitiram avaliar a atuação dos diferentes indicadores zootécnicos nos custos de produção e nos indicadores econômicos. A porcentagem de vacas em lactação e a produtividade animal foram os indicadorescommaior representatividade nos parâmetrosdomodeloderentabilidade. 


\section{REFERÊNCIAS}

BERETTA, V.; LOBATO, F. P.; MIELITZ, N. Produtividade e eficiência biológica de sistemas pecuários de cria diferindo na idade das novilhas ao primeiro parto e na taxa de natalidade do rebanho no Rio Grande do Sul. Revista Brasileira de Zootecnia, v. 30, n. 4, p. 1278-1286, 2001.

CAMILO NETO, M. Análise de indicadores zootécnicos e econômicos de fazendas leiteiras em Ituiutaba-Minas Gerais. 2008. 34f. Dissertação (Programa de Pós-Graduação Profissionalizante em Zootecnia) - Departamento de Zootecnia da Universidade Federal de Viçosa, Viçosa, 2008.

FERRAZZA, R. A.; LOPES, M. A.; MORAES, F.; BRUHN, F. R. P. Índices de desempenho zootécnico e econômico de sistemas de produção de leite com diferentes níveis tecnológicos. Semina: Ciências Agrárias, v. 36, n. 1, p. 485-496, 2015 .

GOMES, S. T. Cuidados no cálculo do custo de produção de leite. In: SEMINÁRIO SOBRE METODOLOGIAS DE CÁLCULO DO CUSTO DE PRODUÇÃO DE LEITE, 1. 1999, Piracicaba. Anais... Piracicaba: Universidade de São Paulo, 1999. p. 12-18.

KÖPPEN, W. Climatologia: con un estudio de los climas de la tierra. Mexico: Fondo de cultura economica, 1948.

LINS, P. M. G.; VILELA, P. S. Diagnóstico da pecuária leiteira do Estado de Minas Gerais em 2005: relatório de pesquisa. Belo Horizonte, 2006. FAEMG, 156 p.

LOPES, A. D.; OLIVEIRA, M. D. S.; FONSECA, M. I. Características técnicas das propriedades de baixa escala leiteira observadas na área de abrangência do escritório de desenvolvimento rural de Jaboticabal - SP. Revista Ciência em Extensão, v. 6, p. 32-34, 2010.

LOPES, M. A.; DIAS, A. S.; CARVALHO, F. M.; LIMA, A. L. R.; CARDOSO, M. G.; CARMO, E. A. Resultados econômicos de sistemas de produção de leite com diferentes níveis tecnológicos na região de Lavras - MG nos anos de 2004 e 2005. Ciência e Agrotecnologia, v. 33, n. 1, p. 252-260, 2009. 
LOPES, M. A.; LIMA, A. L. R.; CARVALHO, F. M.; REIS, R. P.; SANTOS, Í. C.; SARAIVA, F. H. Controle gerencial e estudo da rentabilidade de sistemas de produção de leite na região de Lavras (MG). Revista Ciência e Agrotecnologia, v. 28, p. 883-892, 2004.

LOPES, M. A.; LIMA, A. L. R.; CARVALHO, F. M.; REIS, R. P.; SANTOS, I. C.; SARAIVA, F. H. Efeito da escala de produção nos resultados econômicos de sistemas de produção de leite na região de Lavras (MG): um estudo multicasos. Boletim da Indústria Animal, v. 63, p. 177-188, 2006.

LOPES, M. A.; LOPES, D. C. F. Desenvolvimento de um sistema computacional para cálculo do custo de produção do leite. Revista Brasileira de Agroinformática, v. 2, n. 1, p. 1-12, 1999.

MARQUES, V. M.; REIS, R. P.; SÁFADI, T.; REIS, A. J. dos. Custo e escala na pecuária leiteira: estudos de casos em Minas Gerais. Ciência e Agrotecnologia, v. 26, n. 5, p. 1027-1034, 2002.

MARTUSCELLO, J. A. Repetibilidade e Seleção em Panicum maximum. 2007. $111 \mathrm{f}$. Tese (Doutorado em Genética e Melhoramento de Animais Domésticos; Nutrição e Alimentação Animal; Pastagens e Forragicultura) - Departamento de Zootecnia da Universidade Federal de Viçosa, 2007.

MORAES, F.; LOPES, M. A.; BRUNHN, F. R. P.; CARVALHO, F. M.; LIMA, A. R. L.; REIS, E. M. B. Efeito de índices técnicos e gerenciais na rentabilidade da atividade leiteira com diferentes tipos de mão de obra. Archivos Latinoamericanos de Producción Animal, v. 24, n. 1, p. 29-38, 2016.

NASCIF, C. Análise de indicadores técnicos e econômicos para identificar indicadores-referência de sistemas de produção de leite em quatro mesorregióes do estado de Minas Gerais. 2008. 114f. Dissertação (Programa de Pós-Graduação Profissionalizante em Zootecnia) - Departamento de Zootecnia da Universidade Federal de Viçosa, Viçosa, 2008.

OLIVEIRA, A. S.; CUNHA, D. N. F. V.; CAMPOS, J. M. S.; S DO VALE, S. M. L. R.; ASSIS, A. J. Identificação e quantificação de indicadores-referência de sistemas de 
produção de leite. Revista Brasileira de Zootecnia, v. 36, n. 2, p. 507-516, 2007.

REIS, R. P. Fundamentos de economia aplicada. Ed. revisada e ampliada. Lavras: UFLA/FAEPE, 2002. 95 p. (Curso de Pós-Graduação "Latu Sensu" Especialização à distância). Lavras, 2002.

RIBEIRO, E. G.; FONTES, C. A. A.; PALIERAQUI, J. G. B.; MARTINS, C. E.; CÓSER, A. C.; SANT 'ANA, N. F. Influência da irrigação durante as épocas seca e chuvosa na taxa de lotação, no consumo e no desempenho de novilhos em pastagens de capim-elefante e capim-mombaça. Revista Brasileira de Zootecnia, v. 37, n. 9, p. 1546-1554, 2008.

ROBERTS, C. R. Effect of stocking rate on tropical pastures. Tropical Grasslands, Sidney, v. 14, n. 3, p. 225-231, 1980.

SOUSA, M. R. P.; RISTOW, A. M.; NOGUEIRA, E. B.; TORRES FILHO, R. A.; CORTEZ, M. A. S. Caracterização de pequenas unidades produtoras de leite na região centro e noroeste do estado do Rio de Janeiro. Revista Brasileira Ciência Veterinária, v. 18, p. 79-84, 2011.

TEIXEIRA JÚNIOR, F. E. P.; LOPES, M. A.; RUAS, J. R. M.; SILVA, M. A. O. Efeito dos manejos de amansamento de primíparas no pré-parto e do maior peso vivo ao parto na rentabilidade da atividade leiteira. Revista Brasileira Ciência Veterinária, v. 23, n. 2, p. 81-86, 2016.

TUPY, O. Tecnologia e valor econômico agregado à produção de leite. Revista de Política Agrícola, v. 20, n. 1, p. 79-88, 2011.

Recebido em: 04/10/2017

Aceito em: 24/05/2018 